\title{
Case Report \\ Primary Intraparenchymal Squamous Cell Carcinoma of the Kidney: A Rare and Unique Entity
}

\author{
Prithwijit Ghosh $^{1}$ and Kaushik Saha ${ }^{2}$ \\ ${ }^{1}$ DESUN (NEON) Reference Lab, Kolkata, West Bengal, India \\ ${ }^{2}$ Department of Pathology, Murshidabad Medical College and Hospital, Berhampore, Murshidabad, West Bengal, India
}

Correspondence should be addressed to Kaushik Saha; drkaushik.saha@yahoo.com

Received 29 November 2013; Accepted 17 December 2013; Published 20 January 2014

Academic Editors: S. Hussain, E. Miele, and M. M. Picken

Copyright (c) 2014 P. Ghosh and K. Saha. This is an open access article distributed under the Creative Commons Attribution License, which permits unrestricted use, distribution, and reproduction in any medium, provided the original work is properly cited.

Primary squamous cell carcinoma (SCC) of the renal parenchyma is a very unusual entity which needs to be differentiated from primary SCC of renal pelvis, SCC from another primary site, and urothelial carcinoma with extensive squamous differentiation. We are most probably describing the second case of primary SCC of the renal parenchyma in a 51-year-old male who presented with heaviness of right upper abdomen with intermittent pain in right flank. Contrast-enhanced computed tomography (CECT) revealed a mass in the right lower pole of the kidney and histopathology following nephrectomy displayed the features of well-differentiated squamous cell carcinoma without urothelial involvement.

\section{Introduction}

Primary squamous cell carcinoma (SCC) of the renal pelvis is a rare but relatively known entity representing only about 0.5 to $15 \%$ of all the urothelial cancers. It is often unsuspected clinically due to its rarity and inconclusive clinical and radiological features, and hence patients present at advanced stages resulting in poor prognosis [1]. However, extensive review of the literature reveals only a single case of primary SCC of renal parenchyma reported till date [2]. We probably report the second case of primary SCC of renal parenchyma in a 51-year-old man presenting with nonspecific clinical complaints.

\section{Case Report}

A 51-year-old male presented with heaviness of right upper abdomen for last 8 months and dull and intermittent pain in the right flank, off and on for last five months. There was no history of weight loss and hematuria during this period. History of fever with associated urinary complaints was also conspicuously absent. He was a nonsmoker and nonhypertensive. The clinical examination revealed mild pallor and mild tenderness in the right flank. There was no palpable lymph node. On routine hematological investigation, his hemoglobin level was $10.2 \mathrm{~g} / \mathrm{dL}$ and RBCs displayed normocytic normochromic features on peripheral blood film examination. The erythrocyte sedimentation rate (ESR) was $40 \mathrm{~mm}$ after the 1st hour. Serum urea and creatinine values were within normal limits. Urine analysis revealed mild pyuria which was sterile on culture. Urine dipstick test was negative for blood and urinary RBC count was within normal limit. However, mild proteinuria was detected. A solitary heterogeneously enhancing relatively well-delineated mass situated in the lower pole of right kidney was detected on contrast-enhanced computed tomography (CECT) scan without any noticeable infiltration of adjacent organs (Figure 1(a)). Retroperitoneal lymph nodes did not appear to be enlarged on CECT. There was no feature of associated hydronephrosis or calculi. Further, no distant metastases were appreciated on CECT chest or bone scan. He underwent a right total nephrectomy without any complication. On gross examination, the mass was variegated, light tan to yellow, friable (Figure 1(b)) measuring $5.8 \mathrm{~cm} \times 5.5 \mathrm{~cm} \times$ $4.5 \mathrm{~cm}$ confined to the lower pole with cut section revealing areas of hemorrhage and necrosis. The mass did not grossly involve the pelvicalyceal system. There was no calculus or 


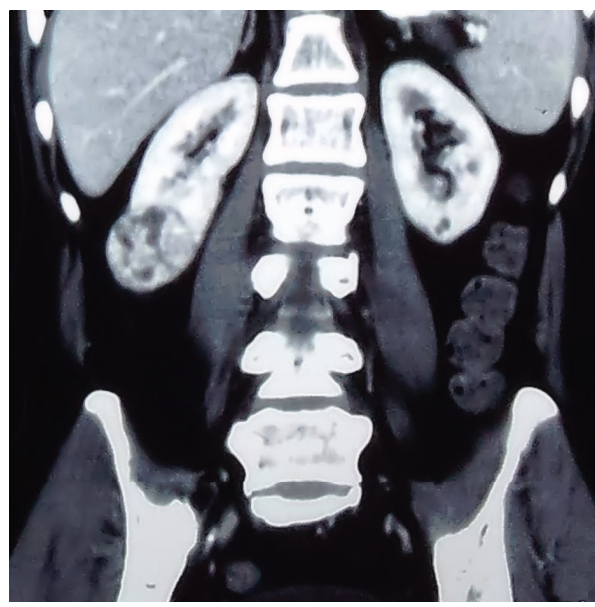

(a)

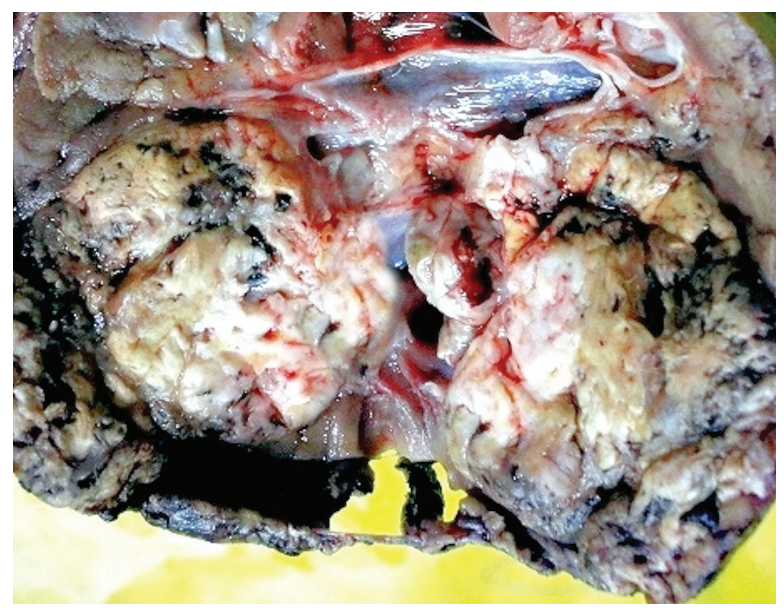

(b)

Figure 1: (a) CECT of abdomen on coronal plane showing a solitary mass in the lower pole of right kidney. (b) Photograph of bisected specimen of nephrectomy showing a well-delineated mass in the lower pole.

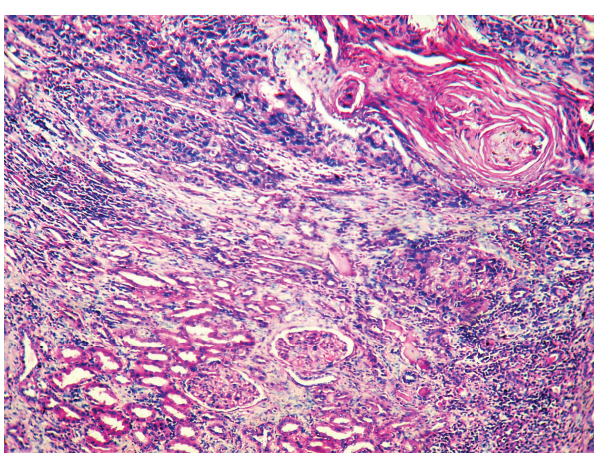

(a)

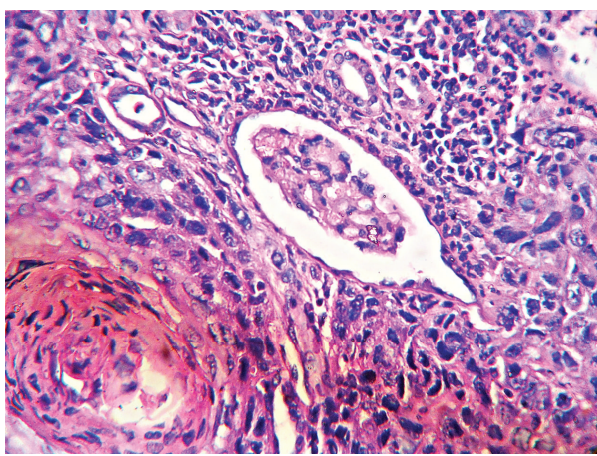

(c)

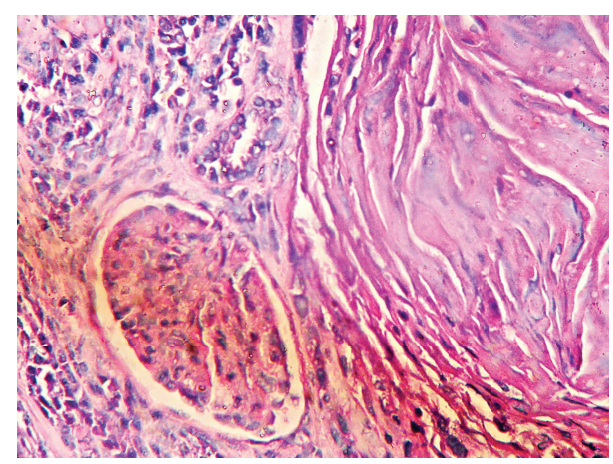

(b)

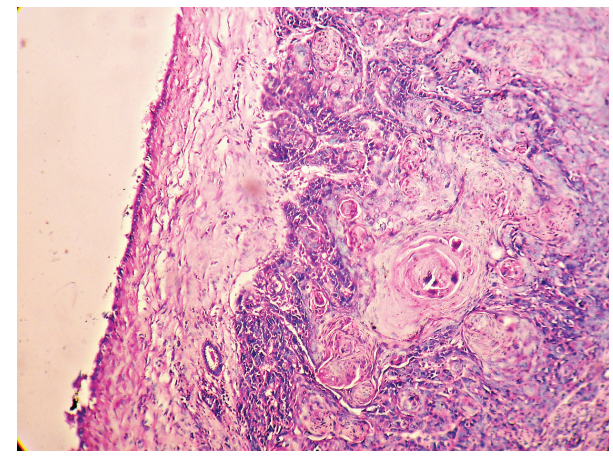

(d)

Figure 2: (a) Photomicrograph of well-differentiated squamous cell carcinoma with keratin pearl formation along with glomeruli and tubules ( $\mathrm{H}$ and $\mathrm{E}, \times 100)$. (b) Glomerulus and tubules in close relation to keratin pearl of squamous cell carcinoma ( $\mathrm{H}$ and $\mathrm{E}, \times 400)$. (c) Photomicrograph of entrapped glomerulus and renal tubules within squamous cell carcinoma (H and E, $\times 400)$. (d) Photomicrograph of uninvolved flattened urothelium of pelvicalyceal system (left) keeping a distance from sheets of malignant squamous cells (right) (H and E, $\times 100)$.

significant cystic dilatation of renal pelvis. Histopathology displayed the features of well-differentiated squamous cell carcinoma with nests of large atypical squamous epithelial cells, keratin pearl formation, and focal areas of necrosis in the renal parenchyma with entrapped glomeruli and tubules (Figures 2(a), 2(b), and 2(c)). The surrounding areas showed a chronic inflammatory reaction. Renal vein, perinephric tissue, and Gerota's fascia remained uninvolved (TNM stage T1bN0M0). Intra- or peritumoral lymphovascular invasion was not detected. Meticulous sampling of the pelvicalyceal system revealed that the nearest urothelium was absolutely free from the tumour mass and did not harbor any feature of squamous metaplasia and of squamous carcinoma in situ (Figure 2(d)). An 18-Fludeoxyglucose positron emission 
tomography/computed tomography (FDG-PET/CT) scan failed to demonstrate any other unknown primary site. The patient did not receive any adjuvant therapy and was alive and doing well after 6 and 12 months of surgical resection with no evidence of recurrence or metastasis.

\section{Discussion}

Transitional cell carcinoma is reportedly the most common type originating in the renal pelvis followed by SCC which is relatively rare and affects predominantly women in the age group of 50 to 70 years. However, SCC of the renal pelvis usually presents at an advanced stage with infiltration of adjacent tissue though both usually tend to have similar prognosis at later stages [3]. In the present case, the tumor was a primary renal intraparenchymal SCC detected in a male patient at an earlier stage with excellent post treatment outcome.

SCC of the urothelial tract is thought to arise through a process of metaplasia mostly keratinizing squamous metaplasia of the urothelium which increases the chances of squamous cell carcinoma in future. The concept of squamous metaplasia as the forerunner of SCC of urothelial tract however has been inflicted with controversies, with differing results from previous studies. The disagreement may partially be due to the relative rarity of SCC of the upper urinary tract [4]. In the presence of an identifiable urothelial dysplastic element including urothelial CIS (carcinoma in situ), the tumor should be classified as primary urothelial carcinoma with squamous differentiation. However, the conspicuous presence of keratinizing squamous metaplasia of the adjacent flattened urothelium, especially if associated with dysplasia, supports a diagnosis of primary SCC of the renal pelvis which is rare $[5,6]$. No such dysplastic urothelial component or metaplastic and/or dysplastic squamous lining of urothelium was found in this case.

The etiological factors, namely, recurrent urinary tract infections with or without vesicoureteric reflux, long standing staghorn calculi, smoking, schistosomiasis, exogenous and endogenous chemicals, vitamin A deficiency, hormonal imbalance, and so forth, are the leading ones in renal pelvis SCC. Only few cases have been reported where no apparent aetiological factor could be detected $[4,7]$. Our case notably lacked the association with such predisposing factors.

Primary SCC of the kidney should further be distinguished from metastatic SCC with the combination of clinical history, imaging studies, and histopathology $[4,8]$.

After ruling out the metastasis, for it to be stamped as a primary renal parenchymal SCC, an extremely rare entity, most importantly the renal pelvis, should be histologically normal, besides other findings as in our case. In the present case, the above-mentioned aetiological factors were absent, CT scan revealed a solitary renal mass, PET scan failed to detect any other unknown primary sites, and histopathological evidence of squamous metaplasia or dysplasia of the urothelium was totally absent despite extensive sampling of the pelvicalyceal region. All these together confirmed the primary intraparenchymal origin of SCC of the kidney. Thus our case shows the need for the consideration of this rare entity in differential diagnosis of renal SCC. As the prevailing data regarding the incidence, histogenesis, disease course, and prognosis of primary intraparenchymal SCC are very inadequate, it needs further future evaluation to provide comprehensive data on this entity.

\section{Conflict of Interests}

The authors declare that there is no conflict of interests regarding the publication of this paper.

\section{References}

[1] A. Jain, D. Mittal, A. Jindal et al., "Incidentally detected squamous cell carcinoma of renal pelvis in patients with staghorn calculi: case series with review of the literature," ISRN Oncology, vol. 2011, Article ID 620574, 6 pages, 2011.

[2] P. Kulshreshtha, N. Kannan, R. Bhardwaj, and S. Batra, "Primary squamous cell carcinoma of the renal parenchyma," Indian Journal of Pathology and Microbiology, vol. 55, no. 3, pp. 370$371,2012$.

[3] R. Bandyopadhyay, S. Biswas, D. Nag, and A. K. Ghosh, "Squamous cell carcinoma of the renal pelvis presenting as hydronephrosis," Journal of Cancer Research and Therapeutics, vol. 6, no. 4, pp. 537-539, 2010.

[4] S. M. Bonsib and L. Cheng, "Renal pelvis and ureter," in Urologic Surgical Pathology, L. Cheng and D. G. Bostwick, Eds., pp. 173193, Mosby/Elsevier, Philadelphia, Pa, USA, 2nd edition, 2008.

[5] A. Lopez-Beltran, R. Montironi, A. Vidal-Jimenez, and L. Cheng, "Pathology of tumors of the urinary bladder," in Clinical Pathology of Urologic Tumors, G. Mikuz, Ed., pp. 57-89, Informa Healthcare, Boca Raton, Fla, USA, 2007.

[6] G. T. Maclennan and L. Cheng, "Renal pelvis and ureter," in Atlas of Genitourinary Pathology, G. T. Maclennan and L. Cheng, Eds., pp. 123-140, Springer, New York, NY, USA, 2011.

[7] N. Talwar, P. Dargan, M. P. Arora, A. Sharma, and A. K. Sen, "Primary squamous cell carcinoma of the renal pelvis masquerading as pyonephrosis: a case report," Indian Journal of Pathology and Microbiology, vol. 49, no. 3, pp. 418-420, 2006.

[8] F. Bhaijee, "Squamous cell carcinoma of the renal pelvis," Annals of Diagnostic Pathology, vol. 16, no. 2, pp. 124-127, 2012. 


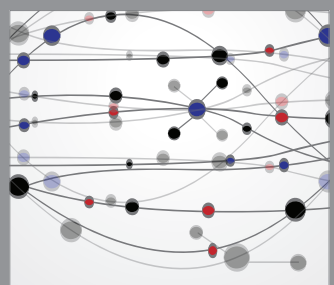

The Scientific World Journal
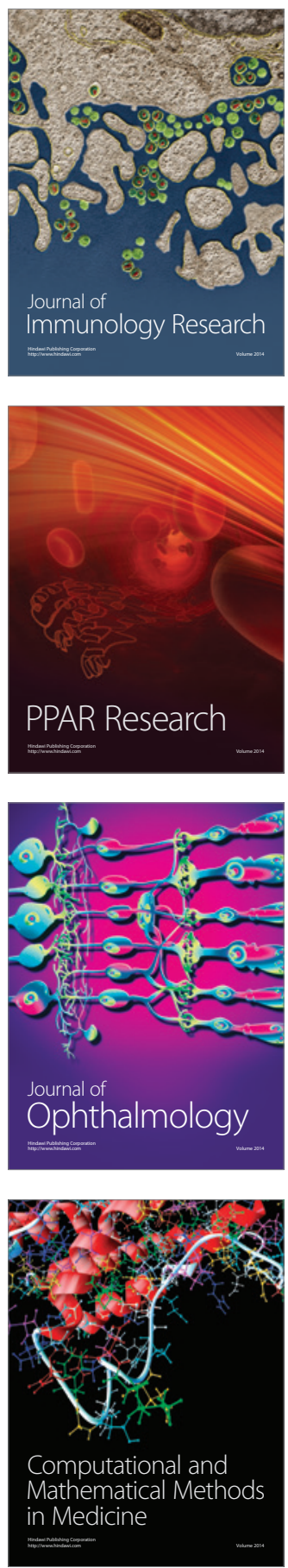

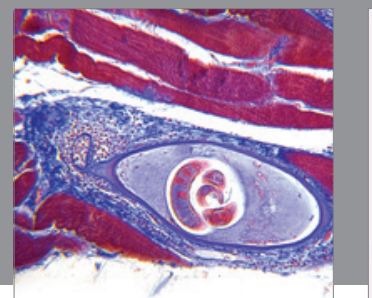

Gastroenterology

Research and Practice
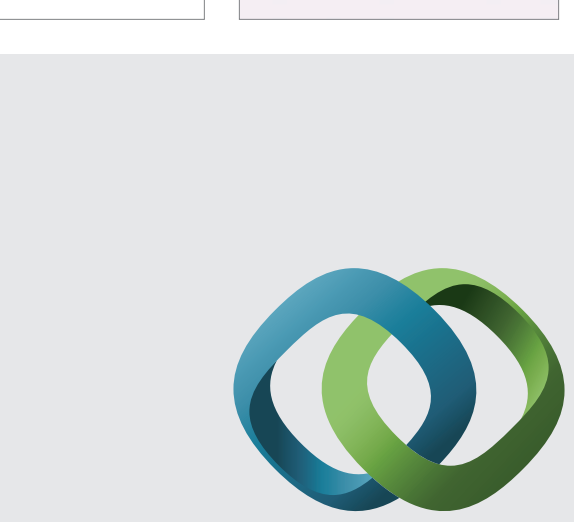

\section{Hindawi}

Submit your manuscripts at

http://www.hindawi.com
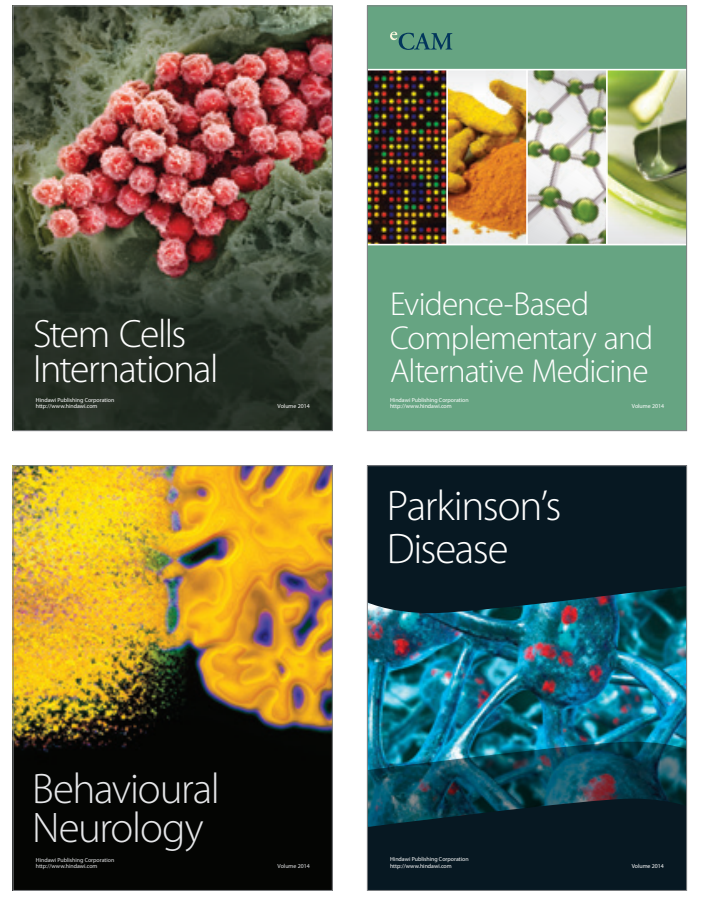
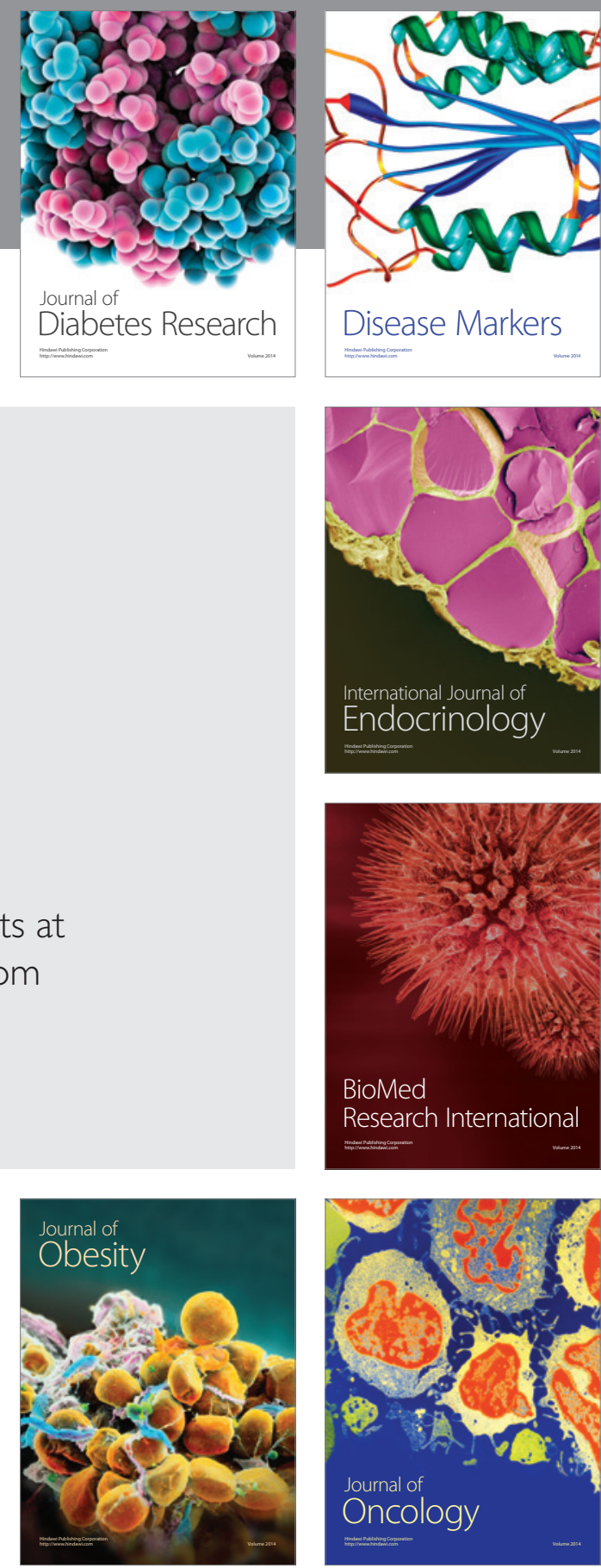

Disease Markers
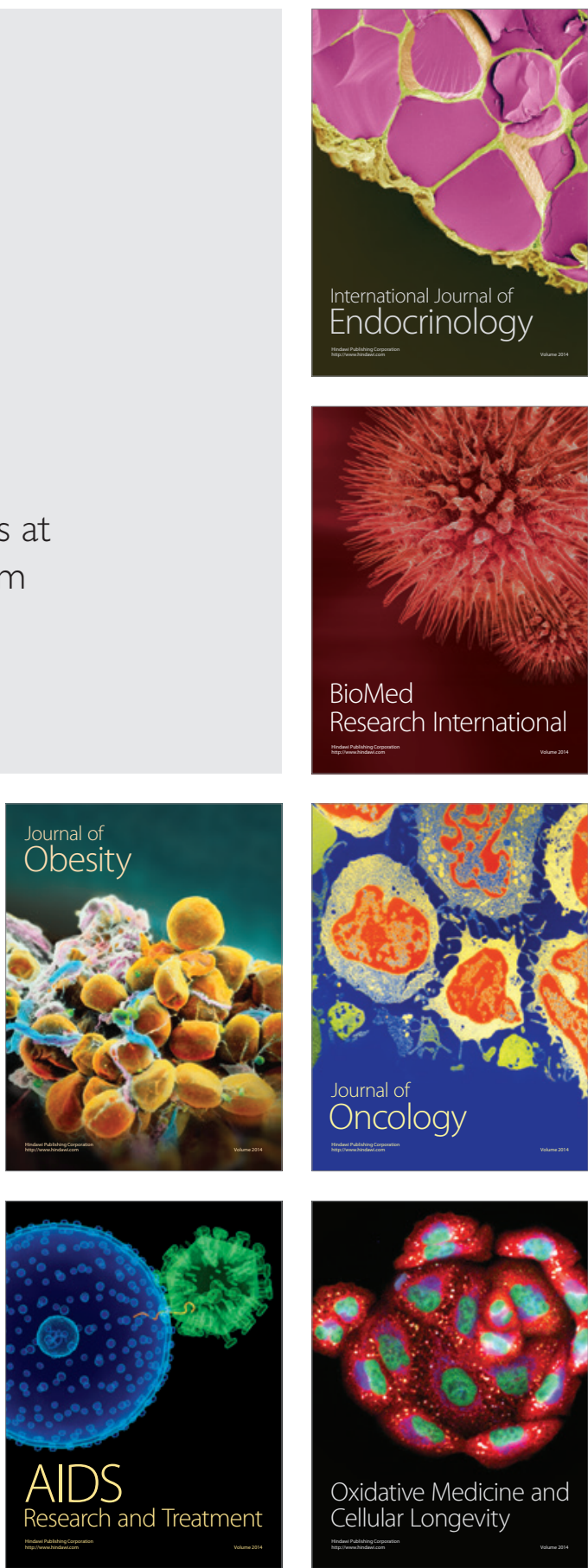